\title{
EFEKTIFITAS PIJAT TUI NA DALAM MENGATASI KESULITAN MAKAN PADA BALITA DI RW O2 KELURAHAN WONOKROMO SURABAYA
}

\author{
Annif Munjidah \\ Fakultas Keperawatan dan Kebidanan \\ Universitas Nahdlatul Ulama Surabaya Jl. Smea No. 57 Surabaya \\ Email: annifmunjidah@unusa.ac.id
}

\begin{abstract}
Abtract: The Effectivity of Tui Na massage to overcome feeding difficulties in infants in $\boldsymbol{R} W 02$ of Wonokromo District Surabaya. The children's growth and development depends on the fulfillment of nutrients. Some problems which often occur in the fulfillment of nutrient are feeding difficulty in infants which can cause growth interference or stunting. The common cause of feeding difficulty in infants is divided into 3 factors, such as loss of appetite, impaired gastrointestinal function, and disruption of eating process of oral motor. To overcome feeding difficulty can be done through pharmacology or non pharmacology. The efforts of pharmacology way such as by giving miltivitamin, and another micronutrient. While non pharmacology way such as through drink herbal / herbs, massage, acupressure, and acupuncture. This study aims to analyze the effectivity of Tui Na massage in overcome feeding difficulty in infants. This was an observational analytic with crosssectional approach. The population used was all mothers and infants who are living in RW 02 Wonokromo District Surabaya as 27 people. The sample used is mostly mothers and the infants who were living in RW 02 of Wonokromo District Surabaya was 23 people. Its used a simple random sampling. The data were analyzed by Chi Square test with significant value alpha $=0.05$. The results showed that the $\mathrm{p}$ value $0.009<\alpha 0.05$. Tui $\mathrm{Na}$ massage is effective to overcome feeding difficulty in infants in RW 02 Wonokromo District Surabaya. The conclusions of this study is the more routine Tui $\mathrm{Na}$ massage is done, the easier way to overcome feeding difficulty. It is expected that the infant's mother are capable and routine to apply this massage
\end{abstract}

\begin{abstract}
Abstrak: Efektifitas pijat Tui Na dalam mengatasi kesulitan makan pada balita di RW 02 Kelurahan Wonokromo Surabaya. Pertumbuhan dan perkembangan anak sangat bergantung pada pemenuhan nutrisi. Beberapa masalah yang sering terjadi dalam pemenuhan nutrisi yakni kesulitan makan pada balita yang dapat menyebabkan terjadinya gangguan tumbuh kembang atau stunting. Penyebab umum kesulitan makan pada bayi dibedakan dalam 3 faktor, diantaranya adalah hilangnya nafsu makan, gangguan fungsi saluran cerna, dan gangguan proses makan atau gangguan oral motor. Upaya untuk mengatasi kesulitan makan dapat dilakukan dengan cara farmakologi maupun non farmakologi. Upaya dengan farmakologi antara lain dengan pemberian miltivitamin, dan micronutrien lainnya. Sedangkan non farmakologi antara lain melalui minuman herbal / jamu, pijat, akupresur, dan akupunktur. Penelitian ini bertujuan untuk mengetahui efektifitas pijat Tui $\mathrm{Na}$ dalam mengatasi kesulitan makan pada balita. Penelitian analitik observasional dengan pendekatan cross sectional. Populasi yang digunakan adalah semua ibu dan balita yang ada di RW 02 Kelurahan Wonokromo Surabaya sebesar 27 orang dan sampel yang digunakan adalah sebagian ibu dan balita yang ada di RW 02 Kelurahan Wonokromo Surabaya. Besar sampel 23 orang. Menggunakan simple random sampling. Analisis data melalui uji Chi Square dengan nilai kemaknaan alpha 0,05. Hasil penelitian menunjukkan nilai p 0,009 < $\alpha$ 0,05. Pijat Tui $N a$ efektif dalam mengatasi kesulitan
\end{abstract}


makan pada balita di RW 02 Kelurahan Wonokromo Surabaya. Simpulan dari penelitian ini semakin rutin pijat Tui $\mathrm{Na}$ dilakukan, maka kesulitan makan pada balita akan teratasi. Diharapkan agar ibu balita mampu dan rutin menerapkan pijat ini.

Kata kunci : pijat Tui Na, kesulitan makan

\section{PENDAHULUAN}

$\begin{array}{ccc}\text { Setiap } & \text { orang tua menginginkan } \\ \text { anaknya tumbuh dengan normal. }\end{array}$
Pertumbuhan (growth) yaitu berkaitan dengan masalah perubahan dalam besar jumlah, ukuran atau dimensi tingkat sel, organ maupun individu, yang bisa diukur dengan ukuran berat (gram, pound, kilogram), ukuran panjang ( $\mathrm{cm}$, meter), umur tulang dan keseimbangan metabolik /retensi kalsium dan nitrogen tubuh. (Soetjiningsih, 2008). Pertumbuhan dan perkembangan anak sangat bergantung pada pemenuhan nutrisi. Beberapa masalah yang sering terjadi yakni kesulitan makan pada balita yang dapat menyebabkan terjadinya gangguan tumbuh kembang, antara lain: daya tahan tubuh menurun, gangguan tidur, gangguan keseimbangan dan koordinasi, juga anak menjadi agresif, impulsif dan stunting.

Di Indonesia dari 23 juta balita, sekitar 7,6 juta anak balita tergolong gagal tumbuh atau stunting $(35,6 \%)$ yang terdiri dari $18,5 \%$ balita sangat pendek dan $17,1 \%$ balita pendek. Angka prevalensi ini diatas ambang batas yang disepakati secara universal, batas non public health problem yang ditolerir oleh badan kesehatan dunia (WHO) hanya 20\% atau seperlima dari jumlah total balita di suatu negara. Lebih dari sepertiga (36.1\%) anak Indonesia tergolong pendek ketika memasuki usia sekolah, Prevalensi anak pendek ini semakin meningkat dengan bertambahnya usia, baik pada anak lakilaki maupun perempuan (Depkes RI, 2010). Anak dengan stunting beresiko memiliki IQ 5-10 poin lebih rendah dibanding dengan anak yang normal (Yenni Puspita. 2015). Stunting terjadi akibat kekurangan gizi dan penyakit berulang dalam waktu lama pada masa janin hingga 2 tahun pertama kehidupan seorang anak (Yenni Puspita. 2015). Anak-anak yang mengalami stunting disebabkan kurangnya asupan makanan dan penyakit yang berulang terutama penyakit infeksi yang dapat meningkatkan kebutuhan metabolik serta mengurangi nafsu makan anak (Yenni Puspita, 2015)

Gejala kesulitan makan dijumpai pada usia anak sebesar 25\%, jumlah tersebut akan meningkat sekitar $40-70 \%$ pada anak. Hal ini juga yang sering membuat masalah tersendiri bagi orang tua. Kesulitan makan sering dialami oleh anak terutama rentang usi 1-3 tahun yang disebut juga usia food jag, yaitu anak hanya makan pada makanan yang disukai atau bahkan sulit makan, seringkali hal ini dianggap wajar namun keadaan sulit makan yang berkepanjangan akan menimbulkan masalah pada pertumbuhan dan perkembangan anak. (Afiani L. Ika dkk, 2003). Demikian juga penelitian Joko Widodo di Jakarta tahun 2010 yang menyebutkan pada anak pra sekolah usia 2-3 tahun, didapatkan prevalensi kesulitan makan sebesar 33,6\%. Sebagian besar $79,2 \%$ telah berlangsung lebih dari 3 bulan. Secara umum penyebab umum kesulitan makan pada bayi dibedakan dalam 3 faktor, diantaranya adalah hilangnya nafsu makan, gangguan fungsi saluran cerna, dan gangguan proses makan atau gangguan oral motor. (Joko Widodo, 2012).

Gangguan fungsi limpa dan pencernaan menjadi penyebab paling dominan pada anak dengan kesulitan makan. Gangguan fungsi saluran cerna kronis seperti alergi makanan, intoleransi makanan, penyakit coeliac. Reaksi simpang makanan tersebut tampaknya sebagai penyebab utama 
gangguan-gangguan tersebut. Hal ini bisa dilihat dengan timbulnya permasalahan kesulitan makan. (Rita Yulia, 2012). Beberapa indikator tanda kesulitan makan pada balita yakni: kesulitan mengunyah, menghisap, menelan, memuntahkan atau menyemburkan makanan yang sudah masuk di mulut, memainkan makanan atau makan berlama-lama, sama sekali tidak mau memasukkan makanan kedalam mulut atau menutup rapat mulut, memuntahkan atau menumpahkan makanan, menepis suapan, tidak menyukai banyak variasi makanan, dan kebiasaan makan yang tidak biasa. (Joko Widodo. 2012)

Upaya untuk mengatasi kesulitan makan dapat dilakukan dengan cara farmakologi maupun non farmakologi. Upaya dengan farmakologi antara lain dengan pemberian miltivitamin, dan micronutrien lainnya. Sedangkan non farmakologi antara lain melalui minuman herbal / jamu, pijat, akupresur, dan akupunktur (Wong, 2011). Pijat dan akupresur merupakan metode yang sudah lama ada, namun sangat jarang dilakukan dalam memberikan asuhan pada balita, di masyarakat anak hanya mendapatkan pijat saat baru lahir sampai usia 40 hari atau jika ada masalah otot lainnya. (Shoim, 2006)

Saat ini kebanyakan orang tua mengatasi kesulitan makan anak sebatas pemberian multivitamin tanpa memperhatikan penyebab. Hal tersebut akan berdampak negatif jika diberikan dalam jangka waktu yang lama. Dewasa ini telah dikembangkan dari tehnik pijat bayi, yakni pijat Tui Na. Pijat ini dilakukan dengan tehnik pemijatan meluncur (Effleurage atau Tui), memijat (Petrissage atau Nie), mengetuk (tapotement atau $D a$ ), gesekan, menarik, memutar, menggoyang, dan menggetarkan titik tertentu sehingga akan mempengaruhi aliran energi tubuh dengan memegang dan menekan tubuh pada bagian tubuh tertentu. Pijat Tui Na ini merupakan tehnik pijat yang lebih spesifik untuk mengatasi kesulitan makan pada balita dengan cara memperlancar peredaran darah pada limpa dan pencernaan, melalui modifikasi dari akupunktur tanpa jarum, teknik ini menggunakan penekanan pada titik meridian tubuh atau garis aliran energi sehingga relatif lebih mudah dilakukan dibandingkan akupuntur (Sukanta, 2010).

Akupresur memiliki sistem dan titik terapi yang cukup banyak, sehingga jika akupresur harus dilakukan di keseluruhan titik maka metode ini akan cukup sulit dilaksanakan oleh bidan ataupun keluarga pasien sebagai asuhan rutin pada anak balita, padahal pada dasarnya setiap titik pada metode akupresur memiliki fungsi tertentu sesuai kebutuhan fisik klien, sehingga akupresur dapat menjadi sangat mudah untuk dilakukan jika terpusat pada titik terkait yang sesuai dengan kebutuhan saja, misalnya pada Pijat Tui Na ini yang terbatas pada titik meridian tangan, kaki, perut dan pungung. Ketentuan pijat ini yakni 1 set terapi sama dengan1 $\mathrm{x}$ protokol terapi per hari, selama 6 hari berturut-turut, bila perlu mengulang terapi beri jeda 1-2 hari dan pijat salah satu sisi tangan saja, tidak perlu kedua sisi, jangan paksa anak makan karena akan menimbulkan trauma psikologis. berikan asupan makanan yang sehat, bergizi dan bervariasi (dr. Tiwi dan Reza, 2013)

Hasil penelitian Zhen Huan Liu dan Li ting Cen di Guangzhou tahun 2009 menyebutkan bahwa pijat Tui na berpengaruh positif terhadap perkembangan syaraf dan peredaran darah pada bayi. Penelitian serupa juga dilakukan oleh Mehta (2002) didapatkan bahwa akupresur pada titik meridian tertentu dapat memperlancar aliran darah ke pencernaan

Berdasarkan hal tersebut peneliti perlu mengkaji lebih lanjut efektifitas pijat Tui $\mathrm{Na}$ dalam mengatasi kesulitan makan pada balita, dengan tetap mengedepankan keamanan dan asuhan sayang anak. 


\section{METODE PENELITIAN}

Penelitian ini menggunakan desain analitik observasional dengan pendekatan cross sectional dengan meneliti efektifitas pijat $\mathrm{Tui} \mathrm{Na}$ dalam mengatasi kesulitan makan anak. Populasi yang digunakan adalah semua ibu dan balita yang ada di RW 02 Kelurahan Wonokromo Surabaya sebesar 27 orang dan sampel yang digunakan adalah sebagian ibu dan balita yang ada di RW 02 Kelurahan Wonokromo Surabaya. Besar sampel 23 orang. Menggunakan simple random sampling. analisis data menggunakan Chi Square dengan nilai kemaknaan alpha 0,05

Pengumpulan data secara langsung menggunakan insrumen lembar kuesioner tentang tanda-tanda kesulitan makan pada balita. Sedangkan untuk variabel pijat Tui $\mathrm{Na}$ yakni perlakuan pijat pada anak selama 6 hari oleh orang tua

Pelaksanaan penelitian ini dilakukan di RW 02 Kelurahan Wonokromo Surabaya. Sedangkan waktu pelaksanaannya dilakukan pada bulan April-Juli 2015

Uji Korelasi Chi Square dengan menggunakan bantuan komputer melalui program SPSS 17

\section{HASIL}

Penelitian ini telah dilakukan di RW 02 Kelurahan Wonokromo. Dimana lokasi penelitian berjarak kurang lebih $1 \mathrm{KM}$ dari Universitas Nahdlatul Ulama Surabaya. Pelayanan kesehatan yang dekat dengan tempat penelitian yaitu Puskesmas Wonokromo, RS. Islam Surabaya.

Kegiatan pelayanan kesehatan melalui posyandu di RW 02 juga terlaksana dengan baik. Setiap hari kamis minggu pertama setiap bulan selalu diadakan kegiatan posyandu yang melibatkan kader, petugas kesehatan dari puskesmas dan tidak jarang dosen dan mahasiswa Unusa terlibat dalam pengabdian masyarakat dan penelitian di acara posyandu tersebut.
Pengumpulan data pada variabel pijat Tui Na dilakukan secara langsung, melalui pembagian kuisioner pada orang tua. Dengan ketentuan pijat dilakukan dengan rutin jika orang tua memberikan $1 \mathrm{x}$ protokol pijat yaitu $1 \mathrm{x} /$ hari yang meliputi 8 gerakan. Sedangkan untuk variabel kesulitan makan pada anak, pengumpulan data dilakukan secara langsung, yaitu peneliti menyebarkan kuisioner berupa 8 indikator kesulitan makan pada balita

1. Distribusi responden berdasarkan usia Karakteristik Responden Menurut Usia Balita

Tabel 1 Distribusi Frekuensi Usia Balita Di RW 02 Kelurahan Wonokromo

\begin{tabular}{cccc}
\hline No & Usia (tahun) & Frekuensi & $\begin{array}{c}\text { Persentase } \\
(\%)\end{array}$ \\
\hline 1 & $7-<36$ bulan & 13 & 56,5 \\
\hline 2 & $36-59$ bulan & 10 & 43,5 \\
\hline \multicolumn{2}{c}{ Total } & 23 & 100 \\
\hline
\end{tabular}

Sumber: data primer Juli 2015

Berdasarkan tabel 1 diatas, diketahui bahwa lebih dari separo responden $(59 \%)$ berusia $7 \mathrm{~s} / \mathrm{d}<36$ bulan

2. Distribusi responden berdasarkan perlakukan pijat $\mathrm{Tui} \mathrm{Na}$

Karakteristik responden berdasarkan perlakukan pijat Tui $\mathrm{Na}$ akan disajikan dalam tabel sebagai berikut:

Tabel 2. Distribusi Frekuensi perlakukan pijat $\mathrm{Tui} \mathrm{Na}$ Di RW 02 Kelurahan Wonokromo

\begin{tabular}{cccc}
\hline No & Pijat & Frekuensi & $\begin{array}{c}\text { Persentase } \\
(\%)\end{array}$ \\
\hline 1 & Rutin melakukan & 8 & 34,8 \\
\hline 2 & $\begin{array}{c}\text { Tidak rutin } \\
\text { melakukan }\end{array}$ & 15 & 65,2 \\
\hline & Total & 23 & 100 \\
\hline
\end{tabular}

Sumber: data primer Juli 2015 
Berdasarkan tabel 2 diketahui bahwa sebagian besar responden $(65,2 \%)$ tidak melakukan pijat $\mathrm{Tui} \mathrm{Na}$ secara rutin

3. Distribusi responden berdasarkan tingkat kesulitan makan

Karakteristik responden berdasarkan tingkat kesulitan makan akan disajikan dalam tabel sebagai berikut:

Tabel 2. Distribusi Frekuensi tingkat kesulitan makan Balita Di RW 02 Kelurahan Wonokromo

\begin{tabular}{cccc}
\hline No & $\begin{array}{c}\text { Tingkat } \\
\text { Kesulitan } \\
\text { makan }\end{array}$ & Frekuensi & $\begin{array}{c}\text { Persentase } \\
(\%)\end{array}$ \\
\hline 1 & Sulit & 17 & 74 \\
\hline 2 & Tidak sulit & 6 & 26 \\
\hline & Total & 23 & 100 \\
\hline
\end{tabular}

Sumber: data primer Juli 2015

Berdasarkan tabel 2 diketahui bahwa sebagian besar responden (74\%) masih mengalami kesulitan makan

4. Efektifitas pijat Tui Na dalam mengatasi kesulitan makan balita

Berdasarkan hasil uji statistik, karena syarat uji Chi Square tidak terpenuhi maka peneliti menggunakan uji Exact fisher, didapatkan nilai signifikan $\mathrm{p}=$ $0,009<\alpha=0,05$. Maka Ho ditolak Artinya pijat Tui $\mathrm{Na}$ efektif dalam mengatasi kesulitan makan pada balita

\section{PEMBAHASAN}

\section{Pijat Tui $\mathrm{Na}$}

Berdasarkan tabel 2 didapatkan hasil bahwa sebagian besar responden $(65,2 \%)$ tidak melakukan pijat Tui $\mathrm{Na}$ secara rutin. Dari 23 responden hanya 8 orang yang melakukan pijat secara rutin pada anak. Dikatakan rutin jika pijat dilakukan 1 set terapi sama dengan $1 \mathrm{x}$ protokol terapi per hari, selama 6 hari berturut-turut meliputi 8 gerakan (dr. tiwi dan Reza, 2013).
Dikatakan tidak melakukan secara rutin jika tidak setiap hari melakukan atau dalam 1x protokol pijat tidak semua gerakan dilakukan, pada hasil penelitian menunjukkan sebesar 15 orang $(65,2 \%)$ tidak melakukannya dengan rutin.

Dari kuisioner yang disebar sebagian besar orang tua tidak melanjutkan pijatan sampai dengan selesai (8 gerakan). Saat melakukan gerakan yang kedua anak sudah tidak mau. Dan orang tua kesulitan dalam menyelesaikan pijatan sampai dengan selesai. Hal ini yang menyebabkan pijatan tidak masuk dalam kategori rutin.

\section{Kesulitan makan pada balita}

Berdasarkan tabel 2 diketahui bahwa sebagian besar responden (74\%) masih mengalami kesulitan makan. Jika dilihat dari mayoritas responden yakni pada tabel 1 bahwa usia responden paling banyak antara 7 bulan sampai < 36 bulan $(56,5 \%)$. Hal ini sesuai teori bahwa kesulitan makan sering dialami oleh anak terutama rentang usi 1-3 tahun yang disebut juga usia food jag, yaitu anak hanya makan pada makanan yang disukai atau bahkan sulit makan (Afiani L. Ika dkk, 2003). Dikategorikan kesulitan makan jika ibu menjawab isian kuisioner lebih dari 2 tanda / indikator kesulitan makan.

Beberapa indikator tanda kesulitan makan pada balita yakni: kesulitan mengunyah, menghisap, menelan, memuntahkan atau menyemburkan makana yang sudah masuk di mulut, memainkan makanan atau makan berlama-lama, sama sekali tidak mau memasukkan makanan kedalam mulut atau menutup rapat mulut, memnuntahkan atau menumpahkan makanan, menepis suapan, tidak menyukai banyak variasi makanan, dan kebiasaan makan yang tidak biasa. (Joko Widodo. 2012)

c. Efektifitas pijat Tui $\mathrm{Na}$ dalam mengatasi kesulitan makan balita

Hasil uji statistik melalui uji Chi Square tidak memenuhi syarat, sehingga peneliti menggunakan uji axact fisher, 
didapatkan nilai signifikan $\mathrm{p} \quad 0,009<\alpha$ 0,05. Maka Ho ditolak Artinya pijat Tui $\mathrm{Na}$ efektif dalam mengatasi kesulitan makan pada balita.

Pijat Tui $N a$ ini dilakukan dengan tehnik pemijatan meluncur (Effleurage atau Tui), memijat (Petrissage atau Nie), mengetuk (tapotement atau $D a$ ), gesekan, menarik, memutar, menggoyang, dan menggetarkan titik tertentu sehingga akan mempengaruhi aliran energi tubuh dengan memegang dan menekan tubuh pada bagian tubuh tertentu. Pijat Tui $\mathrm{Na}$ ini merupakan tehnik pijat yang lebih spesifik untuk mengatasi kesulitan makan pada balita dengan cara memperlancar peredaran darah pada limpa dan pencernaan, melalui modifikasi dari akupunktur tanpa jarum, teknik ini menggunakan tenik penekanan pada titik meridian tubuh atau garis aliran energi sehingga relatif lebih mudah dilakukan dibandingkan akupuntur (Sukanta, 2010).

Penyebab tersering pada kasus kesulitan makan pada balita dikarenakan gangguan fungsi limpa dan pencernaan. Sehingga makanan yang masuk kedalam perut tidak segera dicerna, yang berakibat pada stagnasi makanan dalam saluran cerna, keluhan yang disampaikna orang tua pada masalah ini adalah anak sering muntah, mual jika disuapi, dan perut terasa penuh sehingga mengurangi nafsu makan atau bahkan tidak nafsu makan sama sekali. Pijat ini akan memperlancar peredaran darah ke limpa dan pencernaan, hal ini didukung oleh penelitian yang dilakukan oleh Zhen Huan Liu dan Li ting Cen di Guangzhou tahun 2009 menyebutkan bahwa pijat Tui na berpengaruh positif terhadap perkembangan syaraf dan peredaran darah pada bayi. Penelitian serupa juga dilakukan oleh Joko Widodo dkk (2012) didapatkan bahwa akupresur pada titik meridian tertentu dapat memperlancar aliran darah ke pencernaan

\section{SIMPULAN}

Berdasarkan hasil penelitian ditarik kesimpulan sebagai berikut:

dapat

1. Sebagian besar orang tua tidak melakukan secara rutin pijat $\mathrm{Tui} N \mathrm{Na}$

2. Sebagian besar balita masih mengalami kesulitan makan

3. Pijat Tui Na efektif dalam mengatasi kesulitan makan pada balita

\section{DAFTAR RUJUKAN}

Depkes RI. 2010. Stimulasi Deteksi Intervensi Dini Tumbuh Kembang. Jakarta: UKK tumbuh Kembang

dr. Tiwi dan Reza. Langkah Pijat Tui Na. https://www.youtube.com/watch?v= oDCtwLqgMzc

Ika, Afiani L.dkk. 2003. Ramuan jamu cekok sebagai penyembuhan kurang nafsu makan pada anak. Jurnal Makara kesehatan, Vol. 7, No 1, Juni 2003. UGM: Yogyakarta

Mehta, H. (2002). The Science and Benefits of Acupressure therapy. http://www.associatedcontent.com/a rticle. di akses tanggal 10 Mei 2015

Blog of Pasific collage of oriental medicine. Benefit of Tui Na massage.http://www.pacificcollege. edu/news/blog/2014/12/19/benefitstui-na-massage

Puspita, Yenni. 2015. Faktor dan dampak stunting pada kehidupan balita. Dinas Kesehatan Provinsi Bengkulu. Word Press.

Shoim, Muhammad dkk. 2006. Pengaruh pijat terhadap kenaikan berat badan bayi umur 4 bulan. Jurnal gizi klinik Indonesia. Vol 3 No 02. November 2006:67-70

Soetjiningsih. 2008. Tumbuh Kembang anak. Jakarta: EGC

Sukanta, P. Okta. 2010. Akupressur \& Minuman untuk Mengatasi Gangguan Kesehatan Reproduksi. PT Elex Media Komputindo. Jakarta.

Sukanta, P. Okta. 2010. Pijat Akupresur Untuk Kesehatan. Penebar Plus. 
Jakarta

Widodo, Joko. 2012. Edukasi dan konsultasi sulit makan dan gangguan kenaikan berat badan. Jakarta: Picky Eaters And Grow Up Clinik. http:// pickyeatersclinik.com akses 27 Mei 2015 jam 11.00

Wong, M. Fery. 2011. Panduan Lengkap Pijat. Jakarta: Penebar plus

Yulia, Rita. 2012. Lebih sehat dengan akupresur dan pijat bayi. Jakarta: Salemba Medika

Zhen Huan Liu., Li-ting Cen. 2011. Effect Tui $\mathrm{Na}$ On Neurodevelopment in Premature Infant. Journal of Acupuncture and Tuina Science. Vol. 11, Issue 1, pp7-12. Shanghai Research Institute of Acupuncture and Mer 